\title{
High Temperature and Low Moisture Reduce the Storage Requirement of Freshly Harvested True Potato Seeds
}

\author{
Noël Pallais \\ Physiology Department, International Potato Center, P. O. Box 1558, Lima, Peru \\ Additional index words. Solarium tuberosum, seed dormancy, seed vigor, seed viability, after-ripening, seed development, \\ seed position
}

\begin{abstract}
Freshly harvested, true potato (Solarium tuberosum L.) seeds (TPS) will germinate at $15 \pm 5 \mathrm{C}$, but because of dormancy they must be stored for $\approx 18$ months before they will germinate at $>25 \mathrm{C}$. Effects of seed moisture content (SMC) and temperature in storage on germination and seedling emergence were periodically tested during 18 months for seeds harvested from three positions on the mother plant. Seeds were stored with $37 ., 5 \%$, and $7 \%$ SMC (on a dry weight basis) at 5 and $45 \mathrm{C}$; sublets were removed monthly (1 to 7 months) from $45 \mathrm{C}$ and stored at $5 \mathrm{C}$. Seed dormancy and viability were best preserved in storage at low SMC and low temperature, Seeds stored at 45C and $3 \%$ SMC progressively lost dormancy and, after 4 months of storage, germination was up to $88 \%$ after 4 days at 127C. This rate of germination decreased with further storage. Up to $100 \%$ emergence occurred in 9 days in seeds stored for 18 months at $45 \mathrm{C}$ and $3 \%$ SMC. Seeds stored at $45 \mathrm{C}$ and $5 \%$ SMC lost dormancy in 2 months and $<50 \%$ emergence occurred after 18 months. Seeds stored at $45 \mathrm{C}$ and $7 \%$ SMC deteriorated and became nonviable within 6 months of storage. The position of seed development did not significantly affect seed size or weight. However, seeds produced from the bottom third of the plant (lot A) were the most vigorous after dormancy was released with sufficient storage. This suggests that efforts should be made to produce TPS in the primary branches of the mother plant.
\end{abstract}

The use of true potato seed (TPS) is increasing in tropical and subtropical regions where potato production is feasible but the environment is not conducive to the production and maintenance of pathogen-free seed tubers. However, because of dormancy, the most popular TPS progeny (Serrana $x$ LT-7) germinates with difficulty at $>25 \mathrm{C}$ unless seeds have been stored for $\approx 18$ months (Jim Bryan, personal communication). Sufficient seed storage ( $>18$ months) was essential for vigorous performance of Serrana TPS under field conditions (Pallais et al., 1991). The long after-ripening requirement of dormant TPS and the rising demand for seed increase the risk of farmers planting low germinating TPS. TPS dormancy is not a problem for clonal breeding because gibberellic acid (GA) promotes germination in freshly harvested seed (Bamberg and Hanneman, 1984, Spicer, 1961). But, irrespective of GA treatment emergence of dormant TPS from soil increases considerably as the temperatueapproaches 25C (Malagamba 1988). Moreover, seedlings of dormant TPS that are induced to germinate with GA produce less foliage dry matter (Pallais et al., 1990, 1991). Therefore, reducing the long afterripening requirement of dormant TPS by varying the environmental conditions during storage was an important subject for research.

Cool and dry storage conditions are known to lengthen the afterripening requirement of dormant TPS (Simmonds, 1968). But orthodox seeds, such as TPS, deteriorate rapidly when stored under high-temperature and high-moisture (Ellis and Roberts, 1981). Low seed moisture in storage is needed to preserve TPS vigor after dormancy is lost during after-ripening under moderate (21C) temperature (Pallais and Espinola, 1992). The objective was to study the effects of low seed moisture content (SMC) and high storage temperature on TPS dormancy. The possible influence of seed lot on these effects was also investigated using TPS harvested from different positions on the mother plant. These are normally bulked at harvest time.

Received for publication 28 Mar. 1994. Accepted for publication 1 Dec. 1994. The cost of publishing this paper was defrayed in part by the payment of page charges. Under postal regulations, this paper therefore must be hereby marked advertisement solely to indicate this fact.

\section{Materials and Methods}

The experiments were conducted at the International Potato Center (CIP) in Lima, Peru, using TPS of Serrana x AVRDC produced in Osomo $\left(41^{\circ} \mathrm{S}\right)$, Chile, in April 1991, and provided by Chile's Instituto Nacional de Investigacion es Agropecuarias (INIA) in October 1991. There were three different seed lots, which had been separated at harvest according to the position of the berries on the mother plant. Lot A was harvested from the bottom third position on the mother plant (10-12 weeks postpollination), lot B from the middle third (8- 10 weeks) and lot $\mathrm{C}$ from the top third (68 weeks). SMC on a dry weight basis was determined upon arrival in Peru with a Sartorius thermocontrol infrared dryer (YTC01L), and seeds were stored with 7.68\% (lot A), 7.24\% (lot B) and 7.51\% (lot C) SMC at $15 \mathrm{C}( \pm 5 \mathrm{C})$ before treatments. Physical characteristics were determined by separating all bulk lots received into four different seed sizes using round-hole screens placed over a seed shaker for $4 \mathrm{~min}$, and 10 random samples of $\approx 0.5 \mathrm{~g}$ each were weighed and counted to calculate 100-seed weight (Table 1). All lots were carefully reconstituted to their original bulk state before treatments. Initial laboratory tests based on percentage of germination after 14 days at 20C confined the high viability (>94\%) of all lots.

Storage treatments consisted of drying seeds to $3 \%, 5 \%$, and $7 \%$ SMC at $22 \mathrm{C}$ with silica gel, as previously determined in a seed sample obtained from lot B. Sufficient sublets were sealed airtight and stored separately at 5 and $45 \mathrm{C}$ according to the treatments and evaluations. Monthly germination and emergence tests were conducted simultaneously in the laboratory and greenhouse after 1 to 6 months of storage (data not shown). Each month, seed subsamples were removed from storage at $45 \mathrm{C}$ and stored at $5 \mathrm{C}$. These seeds were tested for germination after 7 months of storage together with seeds that had been stored only at $5 \mathrm{C}(0$ months at $45 \mathrm{C})$ and only at $45 \mathrm{C}$, and for emergence after 14 months. A final seedling emergence test was conducted with seeds that had been stored for 18 months at $45 \mathrm{C}$ only. Before germination and emergence tests, seeds were humidified to an equal SMC of about $13 \%$ by exposing to water vapor at $22 \mathrm{C}$ for $24 \mathrm{~h}$. 
Table 1. Seed physical parameters in three true potato seed (TPS) lots harvested from different positions on the mother plant.

\begin{tabular}{lccc}
\hline & $\begin{array}{c}\text { TPS size } \\
\text { classes } \\
(\mathrm{mm})\end{array}$ & $\begin{array}{c}\text { TPS size } \\
\text { distribution } \\
(\%)\end{array}$ & $\begin{array}{c}100 \text {-seed } \\
\text { wt } \\
(\mathrm{mg})\end{array}$ \\
\hline Bottom third (Lot A) & Bulk & & 78.8 \\
& $>1.46$ & 48 & 86.2 \\
& 1.27 & 31 & 76.4 \\
& 1.15 & 12 & 67.5 \\
Middle third (Lot B) & $<1.15$ & 9 & 55.5 \\
& Bulk & & 82.5 \\
& $>1.46$ & 47 & 89.3 \\
& 1.27 & 33 & 78.1 \\
Top third (Lot C) & 1.15 & 14 & 69.9 \\
& $<1.15$ & 6 & 60.2 \\
& Bulk & & 81.6 \\
& $>1.46$ & 47 & 90.5 \\
& 1.27 & 33 & 79.4 \\
& 1.15 & 14 & 68.7 \\
& $<1.15$ & 6 & 57.9 \\
& CV (\%) & & 1.73 \\
\hline
\end{tabular}

Germination test. Four replications of 100 seeds each were obtained with a sampling spoon using the pie method for random selection. Seeds were germinated in $9-\mathrm{cm}$ petri dishes lined with filter paper moistened with $5 \mathrm{ml}$ of deionized water. Petri dishes were randomized inside an incubator set at $27 \mathrm{C}$ for $21 \mathrm{~h}$ and $40 \mathrm{C}$ for $3 \mathrm{~h}(27 / 40 \mathrm{C})$. After 8 days of germination, the temperature in the incubator was lowered to a constant 20C. Seeds were exposed to light only during evaluations. Germination defined as radicle protrusion was counted daily for 12 days. Germination percentages are given for 4 and 12 days only.

Emergence test. Five replications of 20 seeds each were sown $1 \mathrm{~cm}$ deep in polystyrene flats tilled with a steam-sterilized soil mixture of 1 peatmoss : 1 sand. Seeds were covered with soil immediately after sowing and watered as needed, The temperature in the greenhouse was monitored continuously with a thermohydrograph. Average maximum/minimum temperature during emergence was $38 / 25 \mathrm{C}$ for seeds stored for 14 months and 29/11C for seeds stored for 18 months. The fist appearance of a hypocotyl-hook signified emergence. Emergence was counted daily for 17 days after sowing, and percentage emergence at 10 days is presented for seeds stored for 14 months. Daily emergence data are provided for the treatments that survived 18 months of storage at $45 \mathrm{C}$.

Analysis of variance was used to analyze germination. A completely random design with a three-way factorial arrangement (seed lot $x$ seed moisture $x$ time in storage) was used to analyze germination and a randomized complete-block design was used to analyze emergence. According to the results of ANOVA, all threeway interactions were significant at $P<0.05$. Data on percentage germination at 4 and 12 days and percentage emergence at 10 days were analyzed using 2nd degree orthogonal polynomial method (Steel and Torrie, 1980). Daily emergence means at 18 months of storage were compared using LSD at $\mathrm{P}<0.05$.

\section{Results}

Seeds with SMC of 3\% and 5\% were capable of germinating above $60 \%$ in 4 days during 4 months of storage at $45 \mathrm{C}$ (Fig. $1 \mathrm{~A}$

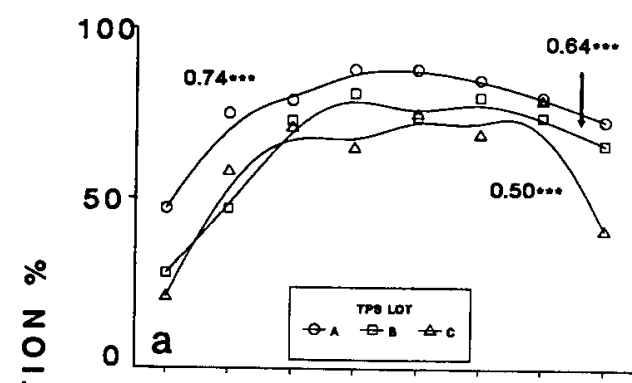

at 4 days

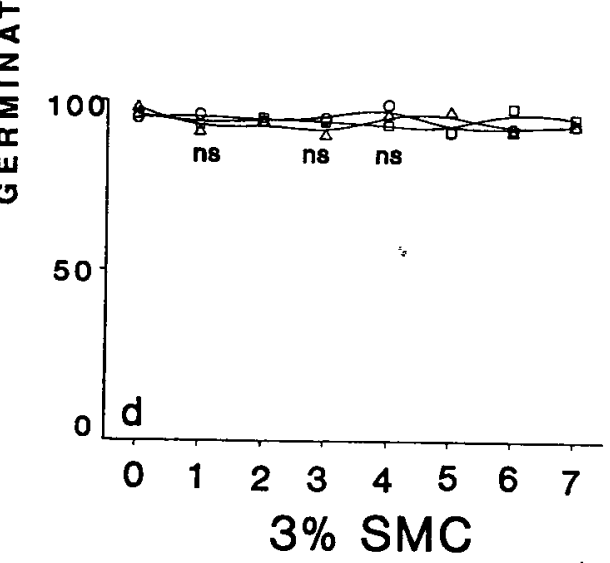

\section{Months in storage at $45 \mathrm{C}$}

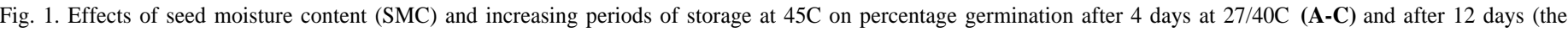

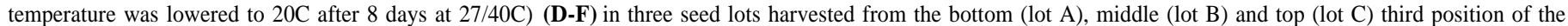

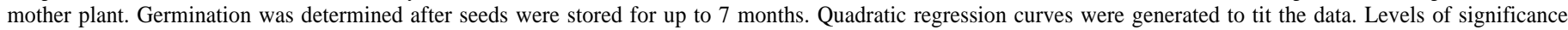
at $P>0.05,<0.05,<0.01$, or $<0.001$ are denoted as $\mathrm{NS}, *{ }^{*} * * * * *$, respectively. 


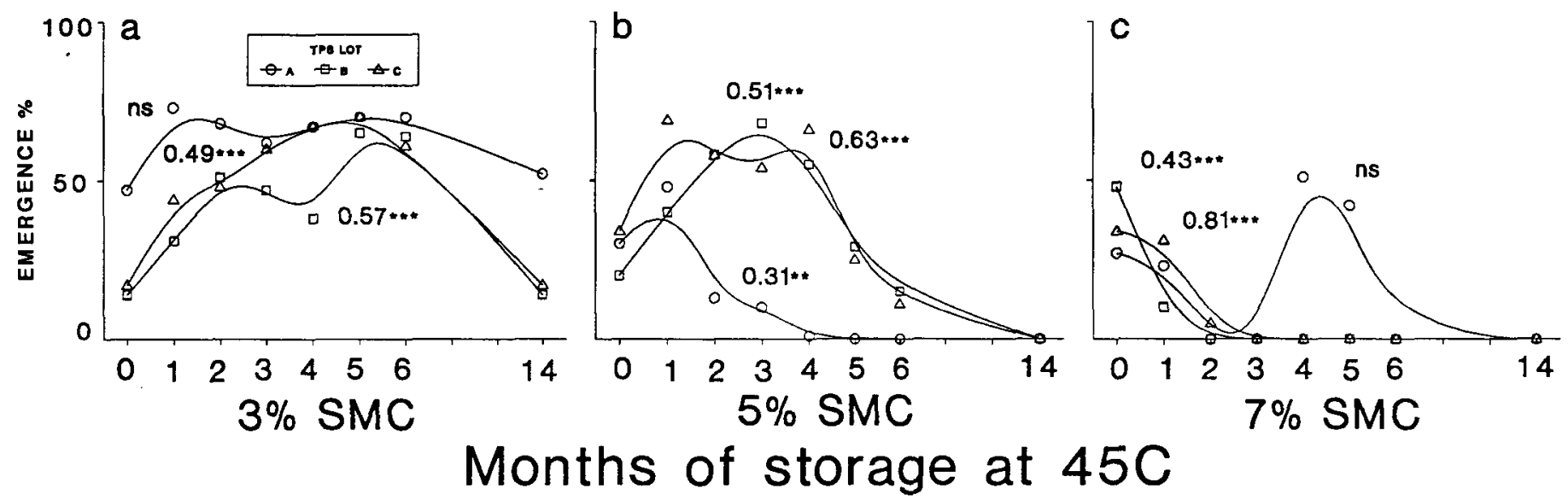

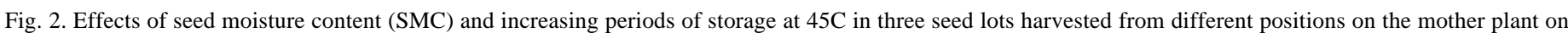
percentage of seedling emergence at 10 days after sowing. Seeds were stored for up to 14 months and seeds were stored at $5 \mathrm{C}$ when not at $45 \mathrm{C}$. For explanations of treatments, analysis and significance, see Fig. 1.

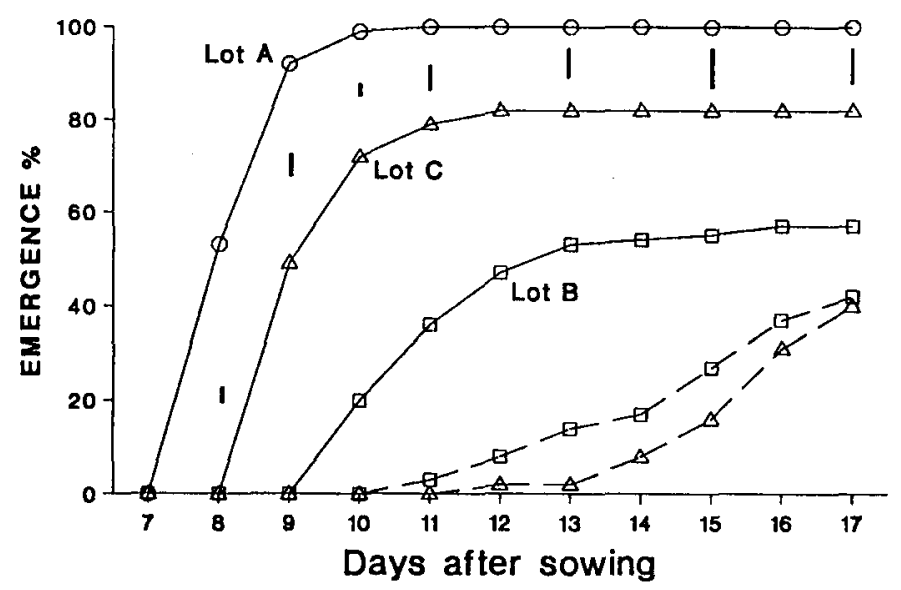

Fig. 3. Effects of seed moisture content (solid line 3\%, dashed line 5\%) on emergence percentage of three seed lots from different parts of the mother plant stored for 18 months at $45 \mathrm{C}$, Seeds stored with $7 \%$ SMC did not emerge. For explanations of treatments see Fig. 1. Bars indicate significance at $P<0.05$ as determined by LSD.

and B). Germination increased at a slower rate in seeds with $3 \%$ SMC compared to those with 5\% SMC, but maximum germination percentages were usually lower and decreased at a faster rate in seeds with 5\% SMC. When seeds were stored with 3\% SMC, germination was always higher for lot A than lots B or C. (Fig. 1A). However, when seeds were stored with $5 \%$. SMC, germination decreased at a faster rate for lot A (Fig. 1B).

Germination at 12 days was always above $90 \%$ when SMC was $3 \%$ during storage (Fig. 1D), and decreased after 5 months of storage in seeds with 5\% SMC (Fig. 1E). In seeds with 7\% SMC, germination percentages (determined at 4 and 12 days) declined after the first month of storage at $45 \mathrm{C}$ (Fig. $1 \mathrm{C}$ and F). However, the abrupt decrease in germination in seeds of lot A stored with $7 \%$. SMC was accompanied by a surprising increase in germination after 3 months of storage followed by a decrease after 5 months.

Although emergence levels (Fig. $2 \mathrm{~A}-\mathrm{C}$ ) were lower than the germination percentages at 4 days (Fig. 1 A-C), the relative effects of the treatments were essentially the same. Emergence percentages in seeds of lot A with 3\% SMC were maintained at $>55 \%$ after 14 months of storage at $45 \mathrm{C}$, while emergence decreased markedly $(<20 \%)$ in lots B and C.

No emergence was obtained when seeds were stored during 18 months with $7 \%$ SMC (Fig. 3). Emergence was $>42 \%$ only when seeds had been stored with 3\% SMC. Lot A was the most vigorous, attaining $100 \%$ emergence 9 days after sowing. Maximum emergence levels were $55 \%$ after 11 days in lot B and $82 \%$ after 15 days in lot C. No seeds of lot A emerged when they were stored with 5\% SMC; however, a few seeds of lots $\mathrm{B}$ and $\mathrm{C}$ emerged after 11 days, increasing to $\approx 40 \%$ at 17 days.

\section{Discussion}

Seeds are considered dormant when they are unable to germinate under environmental conditions which would otherwise be favorable for germination (Côme and Thêvenot, 1982; Karssen, 1982; Khan and Samimy, 1982). Simmonds (1963a) concluded that nondormant TPS should germinate in 2-4 weeks at temperatures of 18-21 C. However, this study shows (Fig. 1A) that nondormant TPS can germinate after only 4 days at temperatures previously considered supra-optimal ( $\geq 27 / 40 \mathrm{C}$ ). Dormant TPS did not germinate under these conditions but germinated fully within 4 days after the temperature was lowered to 20C (Fig. 1D). This supports our previous conclusion (Pallais et al., 1991) that freshlyharvested or dormant TPS germinates readily, but only within a narrow temperature $(15 \pm 5 \mathrm{C})$ range. In agreement with Hilhorst and Karssen (1992), relief from seed dormancy is characterized by an opening of the germination temperature window during afterripening in storage. In 1937, Stier and Cordner had also observed a difference in the germination response to temperature between new and 1-year-old TPS. About 40 species are known to be capable of germinating when freshly harvested only under a narrow range of temperature, which progressively widens as dormancy is lost during after-ripening in dry storage (Roos, 1980). The TPS may now be added to that list.

The results of this study showed that it is possible to significantly decrease the length of storage required for releasing TPS dormancy by after-ripening freshly harvested TPS at high temperature (45C) and very low (3\%) SMC. The practical applicability of these findings was demonstrated at CIP during 1993. A more moderate storage treatment at $40 \mathrm{C}$ and $4 \% \mathrm{SMC}$ for 4 months proved to be effective for after-ripening $12.5 \mathrm{~kg}$ of dormant TPS of a different genotype than that used for this study.

Laboratory tests should attempt to estimate lot performance under the broadest range of possible environmental conditions (Cantliffe and Tigchelaar, 1980) because seed germination under unpredictable field conditions determines the success of crop 
establishment (Norton, 1986). The results of germination at 12 days were generally less reliable (Fig. 1 D-F) for predicting seedling emergence from soil than those of germination after 4 days at $227 / 40 \mathrm{C}$. Rapid germination at $227 / 40 \mathrm{C}$ may be considered a vigor test for TPS as it related reasonably well with the emergence performance of comparable treatments after 14 and 18 months of storage (Figs. 2A and 3).

Maintenance of seed quality poses a serious problem in tropical climates (Ellis, 199 1) where TPS technology is presently being more readily adopted. The data (Fig. $1 \mathrm{C}$ and F) clearly show that germination performance of TPS stored with 7\% SMC declined rapidly in storage at high temperature. SMC levels $>7 \%$, however, would be expected in seeds that are exposed to humid and warm climates. Therefore, extreme caution must be exercised when attempting to after-ripen dormant TPS at high temperature. TPS must always be kept sufficiently dry $(<5 \%$ SMC) inside moistureproof containers.

Gray and Thomas (1982) concluded that the position of the seed on the mother plant influences the levels of endogenous growth regulators, which determine positional differences in seed dormancy characteristics. Evidence of secondary dormancy was found in more mature TPS produced in the bottom third of the plant (lot A) when stored at high temperature and high (7\%) SMC. After 2 months of storage at $45 \mathrm{C}$, germination of lot A was inhibited by induction of a secondary dormancy which was subsequently released after further storage (Figs. $1 \mathrm{C}$ and $\mathrm{F}$ and 2C). This supports Karssen's ( 1982) observation that primary and secondary dormancy may eventually be relieved by the same environmental factors. Induction of secondary dormancy in old TPS in response to unfavorable storage conditions was reported by Simmonds (1963b). The surprising emergence results obtained after 18 months at $45 \mathrm{C}$ (Fig. 3) might be due to differing maturation requirement for the induction of secondary dormancy.

The beneficial effects of increased seed maturity at harvest on germination performance has been demonstrated in many crops (Dean et al., 1989; Delouche, 1980; Gray and Thomas, 1982. This study supports the conclusion (Pallais et al., 1989) that a longer period of seed development on the mother plant also increases the performance of the resulting TPS. In conflict with most published reports (Gray and Thomas, 1982), neither seed size nor weight increased as a consequence of increased seed maturity in the present study (Table 1). In all previous studies it has not been possible to separate positional effects from that of seed size or weight. Thus, the superior seedling vigor found during emergence of lot $\mathrm{A}$ after 14 and 18 months of storage at $45 \mathrm{C}$ and $3 \% \mathrm{SMC}$ (Figs. 2A and 3) is rather unique. Since the quality of TPS produced on the primary inflorescences was superior, efforts should be made to reduce the proportion of seeds produced on secondary and tertiary branches.

\section{Literature Cited}

Bamberg, J.B. and R.E. Hanneman, Jr. 1984. Hastened germination of slow germinating potato seed lots by the use of gibberellic acid and activated charcoal. Amer. Potato J. 61:5 17-5 18

Cantliffe, D.J. and E.C. Tigchelaar. 1980. Introduction to the symposium. HortScience 15:2-8.

Côme, D. and C. Thêvenot. 1982. Environmental control of embryo dormancy and germination. The physiology and biochemistry of seed development, dormancy and germination, p. 27 1-298. In: A.A. Khan (ed.). Elsevier Biomedical Press.

Dean, B. B., T. Noland, and J.D. Maguire. 1989. Correlation of low seed quality with growing environment of carrot. HortScience 24:247-249.

Delouche, J.C. 1980. Environmental effects on seed development and seed quality. HortScience 15:775-780.

Ellis, R.H. and E.H. Roberts. 1981. The quantification of ageing and survival in orthodox seeds. Seed Sci. Technol. 9:373-409.

Ellis, R.H. 1991. The longevity of seeds. HortScience 26:11 19-1 125.

Gray D. and T.H. Thomas. 1982. Seed germination and seedling emergence as influenced by the position of development of the seed on, and chemical application to, the parent plant, p. 8 1-1 10. In: A.A. Khan (ed.). The physiological and biochemistry of seed development, dormancy and germination. Elsevier, New York,

Hilhorst, H.W.M. and C.M. Karssen. 1992. Seed dormancy and germination: the role of abscisic acid and gibberellins and the importance of hormone mutants. Plant Growth Regulat. 11:225-238.

Karssen, C.M. 1982. Seasonal patterns of dormancy in weeds, p. 243-270! In: A.A. Khan (ed.). The physiology and biochemistry of seed development and germination. Elsevier Biomedical Press, New York.

Khan A.A. and C. Samimy. 1982. Hormones in relation to primary and secondary seed dormancy, p. 203-242. In: Khan A.A. (ed.). The physiology and biochemistry of seed development dormancy and germination. Elsevier, New York.

Malagamba, P. 1988. Potato production from true seed in tropical climates. HortScience 23:495-500.

Norton, C.R. 1986. Germination under flooding: Metabolic implications and alleviation of injury. HortScience 21: 1123-1 128.

Pallais, N., H. Asmat, N. Fong, and J. Santos-Rojas. 1989. Factors affecting seedling vigor in potatoes: I. Stage of seed development. Amer. Potato J. 66:793-801.

Pallais, N., N. Fong, R. Garcia, and J. Santos-Rojas. 1990. Factors affecting seedling vigor in potatoes: II. Genotype, after-ripening and pre-sowing treatments. Amer. Potato J. 67: 109-119

Pallais, N. E., N.Y. Espinola, R.M. Falcon, and R.S. Garcia. 1991. Improving seedling vigor in sexual seeds of potato under high temperature. HortScience 26:296-299.

Pallais, N.E. and N. Espinola. 1992. Seed quality as affected by nitrogen during true potato seed production and moisture conditions during storage. Amer. Potato J. 69:85-93.

Roos, E.E. 1980. Physiological, biochemical, and genetic changes in seed quality during storage. HortScience 15:19-22.

Simmonds, N.W. 1963a. Experiments on the germination of potato seeds. I. Eur. Potato J. 6:45-59.

Simrnonds, N.W. 1963b. Experiments on the germination of potato seeds. 11. Eur. Potato J. 6:69-76.

Simmonds, N.W. 1968. Prolonged storage of potato seeds. Eur. Potato J. $11: 150-156$

Spicer, P.B. 1961. Use of gibberellin to hasten germination on Solarium seed. Nature p. 327-328.

Steel, R.G.D. and J.H. Torrie. 1980. Principles and procedures of statistics: A biometrical approach. MacGraw-Hill, New York.

Stier, H.L. and H.B. Cordner. 1937. Germination of seeds of the potato as affected by temperature. Proc. Amer. Soc. Hort. Sci. 34:430-432. 